\title{
Use of PCR-RFLP and PCR-HWP1 for Identification of Candia Species Isolated from Cystic Fibrosis Patients
}

\author{
Peyman Solimani ${ }^{1}$, Samira Salari ${ }^{1}$, Soheila khalizadeh ${ }^{2}$, Maryam Hassanzad ${ }^{2}$, Sadegh Khodavaisy ${ }^{3,4}$, Mahdi Abastabar ${ }^{5}$, Hamed \\ Fakhim hajiaghaei ${ }^{6}$, Hamid Badali ${ }^{5,7 *}$ \\ ${ }^{1}$ Department of Medical Mycology and Parasitology, School of Medicine, Kerman University of Medical Sciences, Kerman, Iran. \\ ${ }^{2}$ Pediatric Respiratory Diseases Research Center, NRITLD, Masih Daneshvari Hospital, Shahid Beheshti University of Medical Sciences, \\ Tehran, Iran. \\ ${ }^{3}$ Department of Medical Mycology and Parasitology, Kurdistan University of Medical Sciences, Sanandaj, Iran \\ ${ }^{4}$ Department of Medical Mycology and Parasitology, Tehran University of Medical Sciences, Tehran, Iran. \\ ${ }^{5}$ Invasive Fungi Research Centre (IFRC)/Department of Medical Mycology and Parasitology, School of Medicine, Mazandaran University of \\ Medical Sciences, Sari, Iran. \\ ${ }^{6}$ Student Research Committee, Mazandaran University of Medical Sciences, Sari, Iran. \\ ${ }^{7}$ Molecular and Cell Biology Research Centre (MCBRC), Mazandaran University of Medical Sciences, Sari, Iran.
}

\section{Received: 4 Mar 2014}

Revised : 1 May 2014

Accepted: 20 May 2014

Corresponding Authors: Hamid Badali

Molecular and Cell Biology Research Centre (MCBRC), Mazandaran University of Medical Sciences, Sari, Iran

Phone: +989128413720

E-mail: badalii@yahoo.com

\begin{abstract}
Background: Due to the predisposing conditions in patients with cystic fibrosis (CF) caused by defective mucociliary clearance facilitates of colonization and invasion with Candida species has dramatically increased. Traditional methods for identification problems are imminent and are time-consuming. Therefore, molecular techniques utilizing amplification of target DNA provide quick and precise methods for diagnosis and identification of Candida species. Therefore, the aim of current study was identification of the most medically common isolated Candida species from the air way of CF patients by PCR-RFLP and amplification of $H W P 1$ gene.

Materials and Methods: A total of $42 \mathrm{CF}$ patients presenting symptoms referred to pediatric respiratory diseases research center were screened for the presence of Candida spp. The isolates initially were phenotypically identified and confirmed by molecular approaches based on restriction fragment length polymorphism (PCR-RFLP) for discrimination of C. albicans of non albicans and amplification of $H W P 1$ gene for discrimination of $C$. albicans from $C$. dubliniensis and $C$. africana was conducted.

Results: Results show that $C$. albicans was the most frequently isolated species (83.8\%) followed by non-albicans included C. parapsilosis (7.1\%), C. glabrata (3.2\%), and C. tropicalis (3.2\%). The restriction patterns of each Candida species were perfectly specific. Since $M s p I$ is not able to discriminate between three morphological related species, $C$. albicans, $C$. dubliniensis and $C$. africana, we used PCR amplification of HWP1 gene, which (7.1\%) species from C. albicans identified as $C$. dubliniensis, however $C$. africana strains were not found.

Discussion: The present study found that $C$. albicans as predominant species isolated from the $\mathrm{CF}$ patients. It can be concluded that molecular diagnostic methods are reliable and would be useful for identification of medically important Candida species in clinical samples. Therefore considerable attention has been paid to prevention and treatment of microbial growth, which has resulted in improvement of patient management.
\end{abstract}

Keywords: Candida species, PCR-RFLP, $H W P 1$ gene, Cystic fibrosis

Please cite this article as: Solimani P, Salari S, khalizadeh S, Hassanzad M, Khodavaisy S, Abastabar M, Fakhim hajiaghaei H, Badali H. Use of PCR-RFLP and PCR-HWP1 for Identification of Candia Species Isolated from Cystic Fibrosis Patients. Res Mol Med. 2014; 2 (3): 23-27 


\section{Introduction}

Cystic fibrosis (CF) is an autosomal recessive disorder that causes abnormalities of ion transport ofepithelial cells and presents as a multisystem disease $(1,2)$. The airways of $\mathrm{CF}$ patients are colonized by pathogenic micro-organisms and the most patients experience recurrent acute respiratory episodes (3). Understanding the microbial flora of the $\mathrm{CF}$ respiratory tract is of considerable importance, as patient morbidity and death are primarily caused bychronic respiratory infections (4). Most studies of CF pathogens have focused on four major bacterial species. Also, both yeasts and filamentous fungi have been identified as microbial pathogens in $\mathrm{CF}(5,6,7)$. One particular fungal genus isolated at high frequencies from sputum culture is Candida and some studies have shown that airway colonization with Candida may cause symptoms in CF patients (8). The frequent use of broad-spectrum antibiotics, impaired salivary secretion, the use of corticosteroid treatments, and CF-related diabetes predisposes $\mathrm{CF}$ patients to colonization of the upper and lower airways with Candida spp. (9-11). It is still controversial whether Candida species are transient or persistent colonizers of the airways or more simply an oral carriage (12). Due to the predisposing conditions of Candida colonization in these patients, identification and discrimination of ethological agents for early treatment, and preventing the invasion is highly recommended. Therefore, due to the high degree of phenotypic similarity between Candida species, identification problems are imminent. Conventional approaches for identification down to the species level are based on morphological and physiological criteria, need several days or weeks to be concluded, and are frequently unspecific. However, today molecular tools are well established. Sequencing of the partial ribosomal operon is relatively expensive. Therefore, alternative molecular assay with high specificity, reproducibility and sensitivity are necessary. Thus the objective of this study was to identification of commonly Candida species isolated from $\mathrm{CF}$ patients by using both polymerase chain reaction-restriction fragment length polymorphism (PCR-RFLP) assay and amplification of HWPl gene.

\section{Materials and Methods}

\section{Yeast isolates}

From February 2012 through April, Forty-two CF patients were surveyed for colonization of their air way by Candida species. Sputum samples were collected from these patients during routine clinical visits or during an admission to the respiratory disease research center in Masih Daneshvari Hospital (Tehran, Iran). The specimens were inoculated onto
Sabouraud dextrose agar containing antibiotics, and incubated at $37^{\circ} \mathrm{C}$ for 2 days. Yeast growth was semi quantitatively noted as none, light $(<10$ colonies), moderate (10-50 colonies), or heavy ( $>50$ colonies). Primarily, these strains were identified by phenotypic methods such as colony color on CHROMagar Candida medium (CHROMagar Company, Paris, France), germ-tube tests in serum at $37^{\circ} \mathrm{C}$ for $2-3 \mathrm{~h}$, microscopic morphology on corn-meal agar (DIFCO laboratories, Detroit, Mich., USA) with 1\% tween 80. One colony on each identification strains was subcultured for molecular identification.

DNA Extraction

Genomic DNA was extracted, using the method of glass bead disruption (13). Briefly, $300 \mu \mathrm{L}$ of lysis buffer (10 mM Tris, $1 \mathrm{mM}$ EDTA (pH 8), 1\% SDS, $100 \mathrm{mM} \mathrm{NaCl}, 2 \%$ triton $\mathrm{X}-100), 300 \mu \mathrm{L}$ of phenolchloroform (1:1) solution and equal to $300 \mu \mathrm{L}$ of 0.5 $\mathrm{mm}$ diameter glass beads, were added to yeast. After 5 min of vigorous shaking which followed by $5 \mathrm{~min}$ centrifugation at $10000 \mathrm{rpm}$, the supernatant was isolated and transferred to a new tube and equal volume of chloroform was added, mixed gently, centrifuged and its supernatant was transferred to a new tube. For alcohol precipitation, $0.1 \mathrm{~mL}$ volume sodium acetate $(\mathrm{pH} 5.2)$ and $2.5 \mathrm{~mL}$ volume of cold absolute ethanol were added and the mixture was gently shaken and centrifuged at $10000 \mathrm{rpm}$ for 10 min at $4{ }^{\circ} \mathrm{C}$. After washing with $70 \%$ ethanol, the pellets resuspended in $100 \mu \mathrm{L}$ TE buffer $(10 \mathrm{mM}$ Tris, $1 \mathrm{mM}$ EDTA) and were stored at $-20^{\circ} \mathrm{C}$ prior to use.

\section{RCR-RFLP analysis}

The PCR-RFLP method was performed as previously described. Briefly, PCR amplification of ITS1-5.8SITS2 rDNA regions was achieved using the universal primers ITS1 (5' -TCC GTA GGT GAA CCT GCG G-3' and ITS4 (5' -TCC TCC GCT TAT TGA TAT GC-3') (MWG-Biotech AG, Germany). To amplify ITS domains, PCR amplification was performed in a final volume of $50 \mu \mathrm{l}$. Each reaction consists of $2 \mu \mathrm{l}$ template DNA, $0.5 \mu \mathrm{l}$ of each primer at $25 \mathrm{pmol}, 1.25$ $\mu \mathrm{l}$ of dNTP (BIORON GmbH, Germany) at $5 \mathrm{mM}$, $0.5 \mathrm{U}$ Taq DNA polymerase (Roche Diagnostics GmbH, Mannheim, Germany) and $5 \mu 110 \times$ PCR buffer. The amplification parameters consist of 35 cycles of denaturation at $94^{\circ} \mathrm{C}$ for $1 \mathrm{~min}$, annealing at $56^{\circ} \mathrm{C}$ for $1 \mathrm{~min}$, extension at $72^{\circ} \mathrm{C}$ for $1 \mathrm{~min}$. In the first cycle, the denaturation step was $94^{\circ} \mathrm{C}$ for $5 \mathrm{~min}$ and in the final cycle the final extension step was $72^{\circ} \mathrm{C}$ for $7 \mathrm{~min}$. Subsequently, PCR products were digested in a final reaction volume of $15 \mu$ l containing $3 \mu \mathrm{l}$ water, $1.5 \mu \mathrm{l}$ buffer, $1 \mathrm{U}$ of restriction enzyme MspI and $10 \mu \mathrm{l}$ PCR product at $37^{\circ} \mathrm{C}$ for $2 \mathrm{~h}$. Amplified and digested products were visualized by 
$1.5 \%$ and $2 \%$ agarose gel electrophoresis in TBE buffer $(0.09 \mathrm{M}$ Tris, $0.09 \mathrm{M}$ boric acid and $2 \mathrm{mM}$ EDTA, pH 8.3) respectively, and stained with ethidium bromide $(0.5 \mu \mathrm{g} / \mathrm{ml})$ and photographed. The size of DNA fragments determined directly with comparison of molecular size marker and distinct banding patterns which demonstrated in similar studies.

\section{PCR-HWP1 for Discrimination of C. albicans complex}

Definitive species identification and discrimination of all members of the $C$. albicans species complex $(C$. albicans, $C$. dubliniensis, $C$. africana, and $C$. stellatoidea) was performed by the amplification of the hyphal wall protein 1 (HWP1) gene as described by Romeo and Criseo (14). PCR amplification of HWP1 gene was achieved using the forward, 5'GCTACCACTTCAGAATCATCATC-3'and reverse, 5'-GCACCTTCAGTCGTAGAGACG-3' primer pairs. The method also identifies because it produces 3 different DNA fragments: approximately $700 \mathrm{bp}$ for C. africana, $941 \mathrm{bp}$ for $C$. albicans, and 569 for $C$. dubliniensis.

\section{Sequence analysis of ITSr DNA region}

Randomly for confirmation the identity of the species sequenced. Sequence analysis of ITS1 and ITS2 regions of the rDNA was performed according to Lott et al. (17) by the company MWG (Eurofins MWG Operon, Ebersberg, Germany) with a Big Dye Terminator Cycle Sequencing Kit on an ABI 3730 Genetic Analyzer (Pleasanton, CA, Usa). The sequences generated were compared to available data in the NCBI database using the Basic Local Alignment Search Tool (BLASTn) (http://www.ncbi.nlm.nih.gov/).

\section{Results}

After the digestion with MspI enzyme the results were evaluated based on the sizes of PCR products for Candida species, i.e. 297, 238 bp for C. albicans; 557, 314 bp for $C$. glabrata; 340, 184 bp for $C$. tropicalis; 261, 249 for C. krusei; $520 \mathrm{bp}$ for $C$. parapsilosis. The ITS regions of all tested isolates were successfully amplified. The digestion of ITS region of Candida species by MspI enzyme created bands for C. albicans, C. glabrata, and C. tropicalis. For $C$. parapsilosis, the size of the PCR and digestion product was similar (Figure 1).

Figure 1 demonstrates the patterns of ITS-RFLP for Candida strains after digestion with MspI. As shown, the fragment lengths were exactly the same as the estimated sizes in the computational sequence analysis. Results show that $C$. albicans was the most frequently isolated species $(83.8 \%)$ followed by non- albicans included C. parapsilosis (7.1\%), C. glabrata $(3.2 \%)$, and C. tropicalis $(3.2 \%)$.

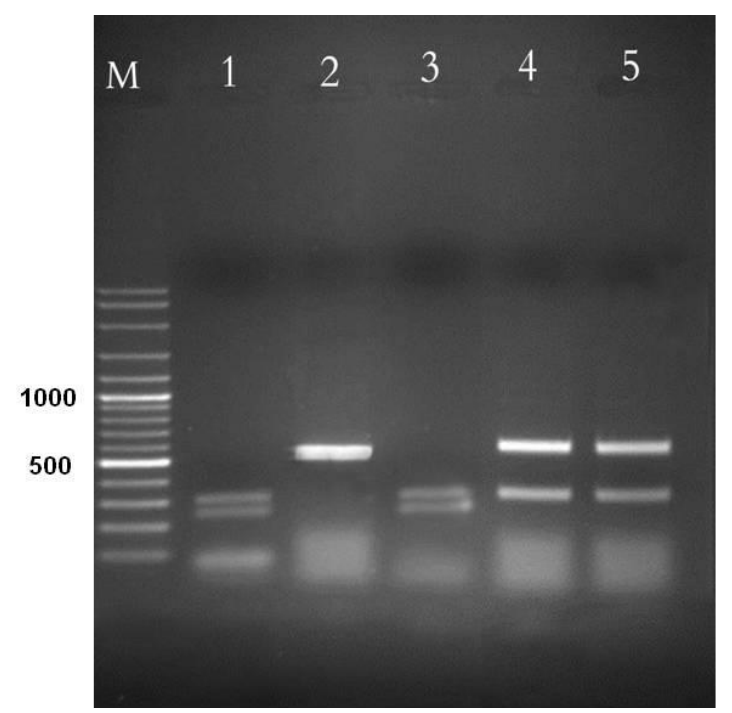

Figure 1. Patterns of PCR products of Candida isolates after digestion by the restriction enzyme MspI. Lanes of 1, 3 represent C. albicans; 2, C. parapsilosis; and 4, C. glabrata. Lane M is 100 bp ladder molecular size marker.

The restriction patterns of each Candida species were perfectly specific. Since MspI is not able to discriminate between three morphological similar species, C. albicans, C. dubliniensis and C. africana, we used PCR amplification of HWP1 gene, which (7.1\%) species from $C$. albicans identified as $C$. dubliniensis; however $C$. africana strains were not found (Figure 2).



Figure 2. Species-specific amplification of the HWP1gene; Lane 1,2 and 4 for $C$. albicans; Lane 3 and 5, for $C$. dubliniensis 


\section{Discussion}

Although recently molecular approaches have been developed for the identification and discrimination of Candida species, novel techniques for the diagnosis based on species level have been established in routine laboratories. These tools are crucially required for the identification of Candida species to reduce morbidity and mortality, and for the treatment of patients suffering from candidiasis. Given the recent evidence that Candida species would be of clinical impact on respiratory function in patient with CF (15-17), we investigated to know the prevalence of Candida species in sputum samples from $\mathrm{CF}$ patients using the PCR-RFLP method.

Consistent with the results of previous studies, the overall Candida colonization rate was high in our study group $(8,11,12)$. A striking result of this study is that $C$. albicans as predominant species isolated from $\mathrm{CF}$ patients. Prior studies showed that $C$. albicans was the most frequent species in the $\mathrm{CF}$ patients $(18,19)$, although, it remains controversial as to whether Candida species are transient or persistent colonizers of the respiratory tract in CF (8). However, the regular assessment of airway colonization is one of the basic guidelines in clinical follow-up of these patients. Newer airway Candida species for example $C$. dubliniensis also emerged over the last decade (20). This new organism was subsequently described in the non-HIV population particularly in individuals receiving high antibiotic burdens such as CF patients (21-23). The present study found that $7.1 \%$ of Candida species isolated from CF patients identified as C. dubliniensis. In this study, molecular analysis performed by amplification of the HWP1 gene showed that $7.1 \%$ of Candida species isolated from $\mathrm{CF}$ patients identified as $C$. dubliniensis. Molecular diagnostic provide a rapid and frequently highly discriminatory means of identifying infectious organisms (24). Use of a PCRRFLP method to identifying infectious organisms is a rapid, almost inexpensive and completely valid method for identification of Candida spp. This method is useful for clinical and epidemiological investigation both mucocutaneous and systemic forms (25). In this study, we apply a PCR-RFLP method to identify the medically important Candida species and similar to other studies, the same results were obtained PCR-RFLP methods in detecting different Candida spp. (24, 26, 27). In conclusion, in this study we found that CF patients are often colonized with Candida species and $C$. albicans as predominant species isolated from this patients. It can be concluded that molecular diagnostic methods are reliable and would be useful for identification of medically important Candida species in clinical samples.

\section{Acknowledgements}

The authors are acknowledged the staff of Masih Daneshvari Hospital and the respiratory disease research center for help in technical assistance for sampling.

\section{References}

1. Davis PB, Drumm M, Konstan MW: Cystic fibrosis. Am J Respir Crit Care Med. 1996; 154: 1229-56. PMID: 8912731

2. Lambiase A, Raia V, Pezzo M, Sepe A, Carnovale V, Rossano F. Microbiology of airway disease in a cohort of patients with cystic fibrosis. BMC Infect Dis. 2006; 6:1-7. PMID: 16405721

3. Lyczak JB, Cannon CL, Pier GB. Lung infections associated with cystic fibrosis. Clin Microbiol Rev. 2002; 15: 194-222. PMID: 11932230

4. Muller FC, Seidler M. Characteristics of pathogenic fungi and antifungal therapy in cystic fibrosis. Expert Rev Anti Infect Ther. 2010; 8: 957-64. PMID: 20695750

5. Salunkhe P, Smart CH, Morgan JA, Panagea S, Walshaw MJ, Hart CA, et al. Cystic fibrosis epidemic strain of Pseudomonas aeruginosa displays enhanced virulence and antimicrobial resistance. J Bacteriol. 2005; 187: 4908-20. PMID: 15995206

6. Alvarez AE, Ribeiro AF, Hessel G, Bertuzzo CS, Ribeiro JD. Cystic fibrosis at a Brazilian center of excellence: clinical and laboratory characteristics of 104 patients and their association with genotype and disease severity. J Pediatr (Rio J). 2004; 80: 371-9. PMID: 15505732

7. Haase G, Skopnik H, Groten T, Kusenbach G, Posselt, HG. Long-term fungal cultures from sputum of patients with cystic fibrosis. Mycoses. 1991; 34: 373-6. PMID: 1820515

8. Chotirmall SH, Greene CM, McElvaney NG. Candida species in cystic fibrosis: a road less travelled. Med Mycol. 2010; 48: 114-24. PMID: 21067323

9. Bakare N, Rickerts V, Bargon J, Just-Nubling G. Prevalence of Aspergillus fumigatus and other fungal species in the sputum of adult patients with cystic fibrosis. Mycoses. 2003; 46(1-2):19-23. PMID: 12588478

10. Bauernfeind A, Bertele RM, Harms K, Horl G, Jungwirth R, Petermuller C, et al. Qualitative and quantitative microbiological analysis of sputa of 102 patients with cystic fibrosis. Infection, 1987; 15(4): 270-7. PMID: 3117700

11. Blaschke-Hellmessen R, Spitzer H, Paul KD, Hoffmann C. Mycological surveillance of children with cystic fibrosis. Mycoses. 1991; 34:43-7. PMID: 1818262

12. Nagano Y, Millar BC, Johnson E, et al. Fungal infections in patients with cystic fibrosis. Rev Med Microbiol. 2007; 18(1): 1116.

13. Mirhendi H, Makimura K, Khoramizade M, Yamaguchi H. A one-Enzyme PCR-RFLP assay for identification of six medically Important Candida species. Jpn J Med Mycol. 2006; 47: 225-9. PMID: 16940958

14. Romeo O, Criseo G. First molecular method for discriminating between Candida africana, Candida albicans, and Candida 
dubliniensis by using hwp1 gene. Diagn Microbiol Infect Dis. 2008; 62: 230-3. PMID: 18640803

15. Sudfeld CR, Dasenbrook EC, Merz WG, Carroll KC, Boyle MP. Prevalence and risk factors for recovery of filamentous fungi in individuals with cystic fibrosis. J Cyst Fibros. 2010; 9: 110-16. PMID: 20045384

16. Chotirmall SH, O’Donoghue E, Bennett K, Gunaratnam C, O'Neill SJ, et al. Sputum Candida albicans presages FEV1' decline and hospital-treated exacerbations in cystic fibrosis. Chest, 2010; 138: 1186-95. PMID: 20472859

17. Leclair LW, Hogan DA. Mixed bacterial-fungal infections in the CF respiratory tract. Med Mycol. 2010; 48: S125-32. PMID: 21067324

18. Muthig M, Hebestreit A, Ziegler U, Seidler M, Muller FM. Persistence of Candida species in the respiratory tract of cystic fibrosis patients. Med Mycol. 2009; 31:1-8. PMID: 19184771

19. Webb AK, Woolnough E. Candida albicans infection in adults with cystic brosis. J R Soc Med. 2006; 99: 13-16. PMID: 16927951

20. Gutierrez J, Morales P, Gonzalez MA, Quindos G. Candida dubliniensis, a new fungal pathogen. J Basic Microbiol. 2002; 42(3):207-27. PMID: 12111748

21. Sullivan DJ, Westerneng TJ, Haynes KA, Bennett DE, Coleman DC. Candida dubliniensis sp. nov.: phenotypic and molecular characterization of a novel species associated with oral candidosis in HIV-infected individuals. Microbiology. 1995; 141 (Pt 7):1507-21. PMID: 7551019

22. Polacheck I, Strahilevitz J, Sullivan D, Donnelly S, Salkin IF, Coleman DC. Recovery of Candida dubliniensis from non-human immunodeficiency virus-infected patients in Israel. J Clin Microbiol. 2000; 38:170-4. PMID: 10618082

23.Peltroche-Llacsahuanga H, Dohmen H, Haase G. Recovery of Candida dubliniensis from sputum of cystic fibrosis patients. Mycoses. 2002; 45:8-15. PMID: 11856431

24. AyatollahiMousavi SA, Khalesi E, ShahidiBonjar GH, Aghighi S, Sharifi F, Aram F. Rapid Molecular Diagnosis for Candida species Using PCR-RFLP. Biotechnology, 2007; 6: 583-7.

25. Cirak YM, Kalkanci A, Kustimur S. Use of molecular methods in identification of Candida species and evaluation of fluconazole resistance. Mem Inst Oswaldo Cruz. 2003; 98:1027-32. PMID: 15049085

26. Pinto PM, Resende MA, Koga-Ito CY, Ferreira JA, Tendler M. rDNA-RFLP identification of Candida species in immunocompromised and seriously diseased patients. Can J Microbiol. 2004; 50:504-20. PMID: 15381977

27. Shokohi T, Hashemi Soteh MB, Pouri ZS, Hedayati MT, Mayahi S. Identification of Candida species using PCR-RFLP in cancer patients in Iran. Indian J Med Microbiol. 2010; 28(2): 14751. PMID: 20404462 